\title{
Descolamento de retina exsudativo bilateral associado a alterações de comportamento em paciente com diaǵnóstico de neurossífilis: relato de caso
}

\author{
Exudativebilateral retinaldetachmentand behaviorchanges \\ in a patient with neurosyphilis: case report
}

\author{
Fernando Korn Malerbi ${ }^{1}$ \\ Ramon Coral Ghanem ${ }^{2}$ \\ Jeane Chiang' ${ }^{3}$ \\ Walter Yukihiko Takahashi ${ }^{4}$
}

Trabalho realizado no Departamento de Oftalmologia do Hospital das Clínicas da Faculdade de Medicina da Universidade de São Paulo - USP - São Paulo (SP) Brasil.

${ }^{1}$ Médico Residente do Departamento de Oftalmologia do Hospital das Clínicas da Faculdade de Medicina da Universidade de São Paulo - USP - São Paulo (SP) Brasil.

Médico Residente do Departamento de Oftalmologia do Hospital das Clínicas da Faculdade de Medicina da USP - São Paulo (SP) - Brasil.

${ }^{3}$ Médico Residente do Departamento de Oftalmologia do Hospital das Clínicas da Faculdade de Medicina da USP - São Paulo (SP) - Brasil.

${ }^{4}$ Médico Assistente-Doutor do Departamento de Oftalmologia do Hospital das Clínicas da Faculdade de Medicina da USP - São Paulo (SP) - Brasil.

Endereço para correspondência: Fernando Malerbi. Rua Jacques Félix, 314/51 - São Paulo (SP) CEP 04509-001

E-mail:femalerbi@terra.com.br

Recebido para publicação em 04.02.2004

Versão revisada recebida em 06.04.2005

Aprovação em 21.07.2005

Cada autor declara que não possui interesse financeiro neste trabalho sob nenhum aspecto.

Nota Editorial: Depois de concluída a análise do artigo sob sigilo editorial e com a anuência dos Drs. Luciana Peixoto Finamor e Moysés Eduardo Zajdenweber sobre a divulgação de seus nomes como revisores, agradecemos sua participação neste processo.

\section{RESUMO}

Objetivo: Descrever caso de descolamento de retina bilateral associado a alterações de comportamento. Resultado: Paciente de 62 anos, sexo feminino, apresentou-se com baixa de visão bilateral, progressiva, de 3 meses de duração, associada a alterações de comportamento e agitação psicomotora. Ao exame oftalmológico apresentava acuidade visual de percepção luminosa em olho direito; e conta dedos a $30 \mathrm{~cm}$ em olho esquerdo. A biomicroscopia evidenciou reação de câmara anterior; à fundoscopia, apresentava edema e hiperemia do disco óptico bilateralmente, áreas extensas de descolamento de retina seroso, placas sub-retinianas amareladas peripapilares e exsudação sub-retiniana e intra-retiniana em ambos os olhos. O exame sorológico para sífilis foi positivo (FTA-Abs e VDRL). A análise liquórica revelou FTA-Abs e teste de hemaglutinação indireta positivos. Foi feito, então, diagnóstico de neurossífilis, e a paciente foi internada para antibioticoterapia endovenosa, e prednisona oral $40 \mathrm{mg} / \mathrm{dia}(0,5 \mathrm{mg} / \mathrm{kg})$. Após 2 semanas, a paciente passou a apresentar melhora importante do quadro ocular com reabsorção da exsudação e melhora da acuidade visual. Conclusão: A sífilis é doença pleomórfica, podendo ter como manifestação ocular uma uveíte difusa associada a descolamento de retina exsudativo bilateral. O envolvimento do sistema nervoso central deve sempre ser considerado e descartado, e o tratamento eficaz da doença pode promover melhora da função visual e diminuir suas seqüelas.

Descritores: Sífilis/diagnóstico; Sorodiagnóstico da sífilis; Sífilis/quimioterapia; Prednisolona/uso terapêutico; Descolamento de retina; Uveíte; Reações falso-positivas; Manifestações neurocomportamentais

\section{INTRODUCÃO}

A sífilis pode ser classificada em formas primária, secundária e terciária. Sua forma terciária ocorre geralmente após dois ou mais anos do contágio inicial, em 25 a $30 \%$ dos pacientes que não foram adequadamente tratados. Dentre os pacientes que atingem a forma terciária, $70 \%$ apresentam cura espontânea, enquanto os $30 \%$ restantes apresentam complicações, das quais as principais são a neurossífilis e a forma cardiovascular ${ }^{(1)}$.

O acometimento ocular na sífilis pode estar presente em qualquer estágio da doença; acometimento do segmento posterior ocorre principalmente nas formas secundária e terciária. Quando, além do quadro ocular, há 
acometimento associado do sistema nervoso central, em $98 \%$ das vezes trata-se da forma terciária ${ }^{(1)}$.

As alterações fundoscópicas na sífilis ocular são muito variadas: pode haver predominantemente uma retinite, uma coroidite, ou um quadro misto; a doença pode também se apresentar como neurite óptica ou como vasculite ${ }^{(1)}$. A análise de uma série de 24 olhos $^{(2)}$ evidenciou que a alteração mais frequiente em uveítes posteriores por sífilis é a vitreíte (63\%). Jumper et al., constataram que o descolamento de retina é uma forma rara de apresentação desta doença ${ }^{(3)}$.

O diagnóstico de sífilis ocular deve ser suspeitado em diversas situações clínicas; pelo fato de ser pleomórfica, o oftalmologista deve considerar o diagnóstico e realizar investigação laboratorial para detectar e tratar esta doença com importante morbidade ocular e sistêmica e que, com o tratamento adequado, pode levar à recuperação visual ${ }^{(1)}$.

\section{RELATO DO CASO}

Paciente de 62 anos, sexo feminino, procurou serviço oftalmológico com agitação psicomotora e queixa de baixa acuidade visual em ambos os olhos há 3 meses; porém, de acordo com depoimento de familiares, a paciente apresentava baixa de acuidade visual há 1 ano. A paciente não apresentava antecedentes mórbidos até então.

Ao exame oftalmológico, a acuidade visual era de percepção luminosa no olho direito (OD) e conta dedos a $30 \mathrm{~cm}$ no olho esquerdo (OE). Os reflexos fotomotores estavam diminuídos simetricamente. Ao exame biomicroscópico, a paciente apresentava reação de câmara anterior $(+2)$ em ambos os olhos e células no vítreo anterior (+1). A pressão intra-ocular era de $14 \mathrm{mmHg}$ em ambos os olhos.

O exame de fundo de olho revelou, bilateralmente, descola- mento de retina com grande presença de líquido sub-retiniano, placas branco-amareladas peripapilares sub-retinianas, lesões exsudativas e hemorragias intra-retinianas (Figura 1).

A angiofluoresceinografia evidenciou hiperfluorescência precoce ao redor do disco óptico e na região correspondente à placa branco-amarelada, mostrando também um extravasamento de fluoresceína nas regiões em que havia descolamento.

A ultra-sonografia evidenciou espessamento sub-retiniano peripapilar e descolamento seroso de retina bilateralmente.

A investigação laboratorial evidenciou VDRL positivo com título de 1/16 e FTA-Abs positivo. A sorologia para HIV foi negativa.

Com diagnóstico de coriorretinite por sífilis, a paciente foi referida ao serviço de infectologia, onde foi realizada punção lombar; a análise do líquor revelou pleocitose, aumento da proteinorraquia, reação de Pandy positiva, sorologia FTAAbs positiva e reação de hemaglutinação indireta para sífilis positiva com título de $1 / 1024$. A tomografia computadorizada de crânio não revelou lesões parenquimatosas ou espessamento meníngeo.

Uma vez estabelecido o diagnóstico de neurossífilis, foi iniciada antibioticoterapia endovenosa com penicilina cristalina 24 milhões de unidades por dia, durante 21 dias, associada a prednisona oral, $40 \mathrm{mg} / \mathrm{d}$, equivalente a $0,5 \mathrm{mg} / \mathrm{kg}$ de peso. Após 1 mês, já havia importante melhora no aspecto fundoscópico, com ausência do descolamento de retina. Foi então iniciada retirada gradativa do esteróide oral.

A paciente foi submetida a nova sorologia e punção lombar para controle após 1 mês; o título do VDRL havia diminuído para $1 / 4 \mathrm{e}$ a reação de hemaglutinação no líquor mostrou um título de $1 / 32$.

Após 3 meses, a paciente apresentava acuidade visual em OD de conta dedos a 2 metros e em OE de 20/200. Não apresentava mais reação de câmara anterior ou vítrea; o fundo de olho
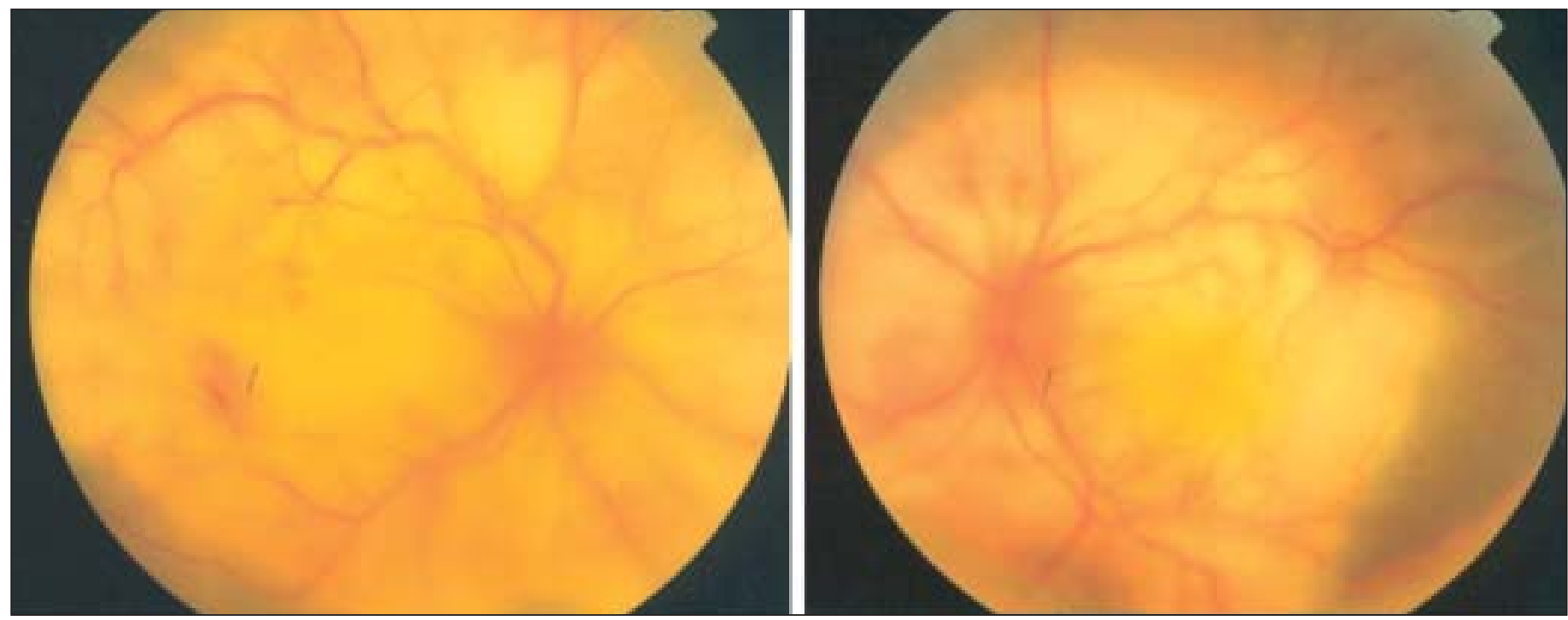

Figura 1 - Retinografia antes do tratamento. Evidenciam-se em ambos os olhos hiperemia e edema do disco óptico, descolamento de retina e placas amareladas subretinianas 
mostrava reabsorção das lesões exsudativas bilateralmente e do líquido sub-retiniano; porém persistiam as placas peripapilares sub-retinianas cicatriciais em região macular. O disco óptico apresentava-se atrófico (Figura 2).

\section{DISCUSSÃO}

No caso relatado, a paciente apresentava uma uveíte difusa bilateral associada a acometimento do sistema nervoso central. Esta forma, chamada de neurossífilis parenquimatosa, geralmente ocorre no estágio terciário, podendo cursar com perda de função cortical, alterações de comportamento e acometimento do liquor (pleocitose, aumento da proteinorraquia, positividade sorológica $)^{(1)}$. A tomografia de crânio pode estar alterada nestas ocasiões, apesar de ter sido normal no presente caso.

Os pacientes com descolamento de retina exsudativo secundário a sífilis apresentam um prognóstico visual reservado, mesmo com o tratamento adequado, evoluindo com espessamento de coróide e atrofia corio-retiniana ${ }^{(3)}$.

Recomenda-se que, feito o diagnóstico de sífilis ocular, proceda-se à análise do líquor, já que, em caso de neurossífilis, a antibioticoterapia é realizada de forma endovenosa. No caso relatado, o líquor estava alterado e, além de auxiliar no diagnóstico, serviu também como controle do tratamento, junto com a sorologia: tanto os títulos do VDRL sérico como da hemaglutinação do líquor diminuíram consistentemente após o tratamento.

Devido à associação entre sífilis e HIV, deve-se também solicitar sorologia para HIV em pacientes com diagnóstico de sífilis. A associação ocorre por diversos motivos: a epidemiologia e as vias de transmissão são semelhantes; além disso, um estado de imunodeficiência pode propiciar o desenvolvimento de manifestações da sífilis. Alguns autores descreve- ram até $70 \%$ de positividade para HIV em pacientes com sífilis ocular $^{(4-5)}$.

Para o diagnóstico laboratorial da sífilis, é sempre necessário solicitar um teste treponêmico (por exemplo, FTA-Abs, ELISA, hemaglutinação). É importante ressaltar que o VDRL, habitualmente solicitado como "screening", não é suficiente para fazer o diagnóstico nem para afastá-lo, pois sua sensibilidade e especificidade são baixas. Em uma série de $21 \operatorname{casos}^{(6)}$, $75 \%$ dos pacientes com sífilis ocular tinham um VDRL negativo; $100 \%$ apresentaram FTA-Abs positivo.

Após o término do tratamento, espera-se que o VDRL negative ou apresente uma diminuição importante dos títulos; ao contrário, o FTA-Abs geralmente permanece positivo como uma "cicatriz" sorológica ${ }^{(1)}$.

Em relação ao tratamento da sífilis ocular, se houver alteração liquórica, o esquema preconizado é penicilina cristalina 24 milhões de unidades endovenosas diárias por 21 dias. Há outros esquemas para casos de alergia a penicilina ${ }^{(1)}$.

Para casos de sífilis ocular com evidência clínica de inflamação corio-retiniana ou neurite óptica ativas, associado ao antibiótico pode ser realizado tratamento com corticosteróide oral, geralmente prednisona, em doses que variam de 0,5 a $1,0 \mathrm{mg} / \mathrm{kg} / \mathrm{d}^{(1)}$. Apesar de não haver estudo controlado recomendando o uso do corticosteróide, a experiência clínica de diversos autores recomenda seu emprego com cautela, desde que associado à antibioticoterapia ou após o término dela. Alguns autores notaram que pacientes que fizeram uso de corticosteróides sem antibióticos tiveram uma evolução pior ${ }^{(7)}$. Outros autores descreveram um caso de um paciente que desenvolveu lesão macular induzida por corticosteróide ${ }^{(8)}$.

$\mathrm{O}$ relato deste caso deve despertar a atenção para o diagnóstico de sífilis em um quadro ocular inespecífico acompanhado de alterações sistêmicas. A sífilis ocular, por sua grande
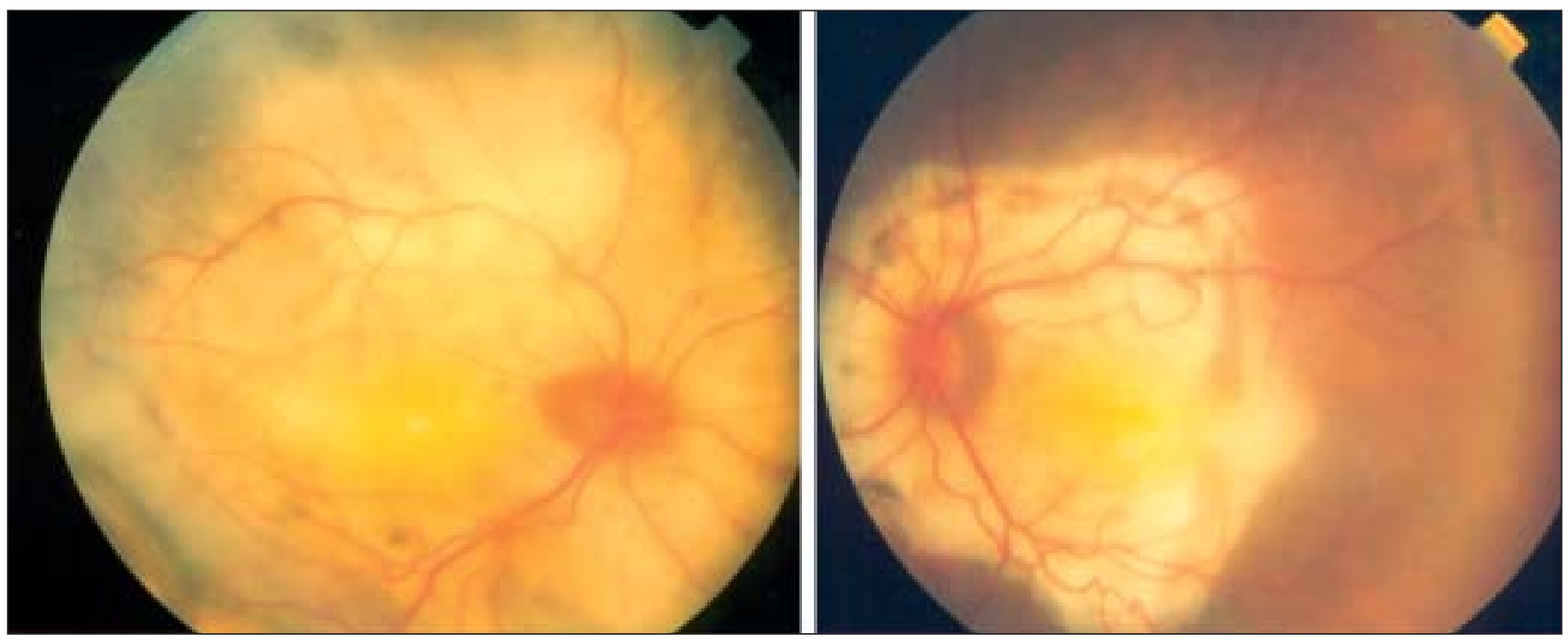

Figura 2 - Retinografia 3 meses após o tratamento. Nota-se melhora do edema do disco óptico e da exsudação sub-retiniana; persistem placas esbranquiçadas subretinianas cicatriciais 
118 Descolamento de retina exsudativo bilateral associado a alterações de comportamento em paciente com diagnóstico de neurossífilis: relato de caso

variedade de apresentações clínicas (“a grande imitadora”(1)), deve ser suspeitada também em uveítes posteriores sem diagnóstico estabelecido. A sífilis é uma doença para a qual existe tratamento eficaz que, se por vezes não melhora de forma significativa a acuidade visual, pode interromper sua progressão, evitando graves conseqüências sistêmicas e oculares.

\section{ABSTRACT}

Purpose: To report a case of bilateral retinal detachment associated with behavior changes. Result: A 62-year-old, female patient presented agitated, complaining of progressive bilateral low vision for the 3 past months, along with anxiety and behavior changes. On examination, she had visual acuity of light perception in the right eye and conting fingers at $30 \mathrm{~cm}$ in the left eye; anterior chamber reaction; bilateral hyperemic and edematous optic disc and bilateral serous retinal detachment, yellow-white subretinal peripapillary plaques and subretinal and intraretinal exudation. On laboratory work-up, the patient had positive VDRL and FTA-Abs tests. Lumbar puncture was done; she had positive FTA-Abs and hemagglutination treponemal test on spinal fluid analysis. Neurosyphilis diagnosis was established, and the patient was admitted to the hospital for an intravenous penicillin course associated with oral prednisone $(0.5 \mathrm{mg} / \mathrm{kg})$. After 2 weeks, the patient showed marked improvement of her retinal findings, with reatachment of the retina and also an improvement of visual acuity. Conclusion: Syphilis is a pleomorphical disease, and may present as diffuse uveitis associated with bilateral exudative retinal detachment. Central nervous system involvement must always be evaluated and discarded; proper treatment may lead to visual function improvement and diminished sequelae.

Keywords: Syphilis/diagnosis; Syphilis serodiagnosis; Syphilis/drug therapy; Prednisone/therapeutic use; Retinal detachment; Uveitis, False positive reactions; Neurobehavioral manifestations

\section{REFERÊNCIAS}

1. Stehling A, Oréfice F. Sífilis. In: Oréfice F. Uveíte clínica e cirúrgica. Rio de Janeiro: Cultura Médica; 2000. p.377-404.

2. Browning DJ. Posterior segment manifestations of active ocular syphilis, their response to a neurosyphilis regimen of penicillin therapy, and the influence of human immunodeficiency vírus status on response. Ophthalmology. 2000;107 (11):2015-23. Comment in: Ophthalmology. 2001;107(11):2015-23.

3. Jumper JM, Machemer R, Gallemore RP, Jaffe GJ. Exudative retinal detachment and retinitis associated with acquired syphilitic uveitis. Retina. 2000;20(2):190-4.

4. McLeish WM, Pulido JS, Holland S, Culbertson WW, Winward K. The ocular manifestations of syphilis in the human immunodeficiency virus type 1infected host. Ophthalmology. 1989;97(2):196-203.

5. Becerra LI, Ksiazek SM, Savino PJ, Marcus DK, Buckley RM, Sergott RC, et al. Syphilitic uveitis in human immunodeficiency virus - infected and noninfected patients. Ophthalmology. 1989;96(12):1727-30.

6. Schlaegel TF Jr, Kao SF. A review (1970-1980) of 28 presumptive cases of syphilitic uveitis. Am J Ophthalmol. 1982;93(3):412-4.

7. Ross WH, Sutton HF. Acquired syphilitic uveitis. Arch Ophthalmol. 1980;98(3): 496-8.

8. Zamani M, Garfinkel RA. Corticosteroid-induced modulation of acute syphilitic posterior placoid chorioretinitis. Am J Ophthalmol. 2003;135(6):891-4.

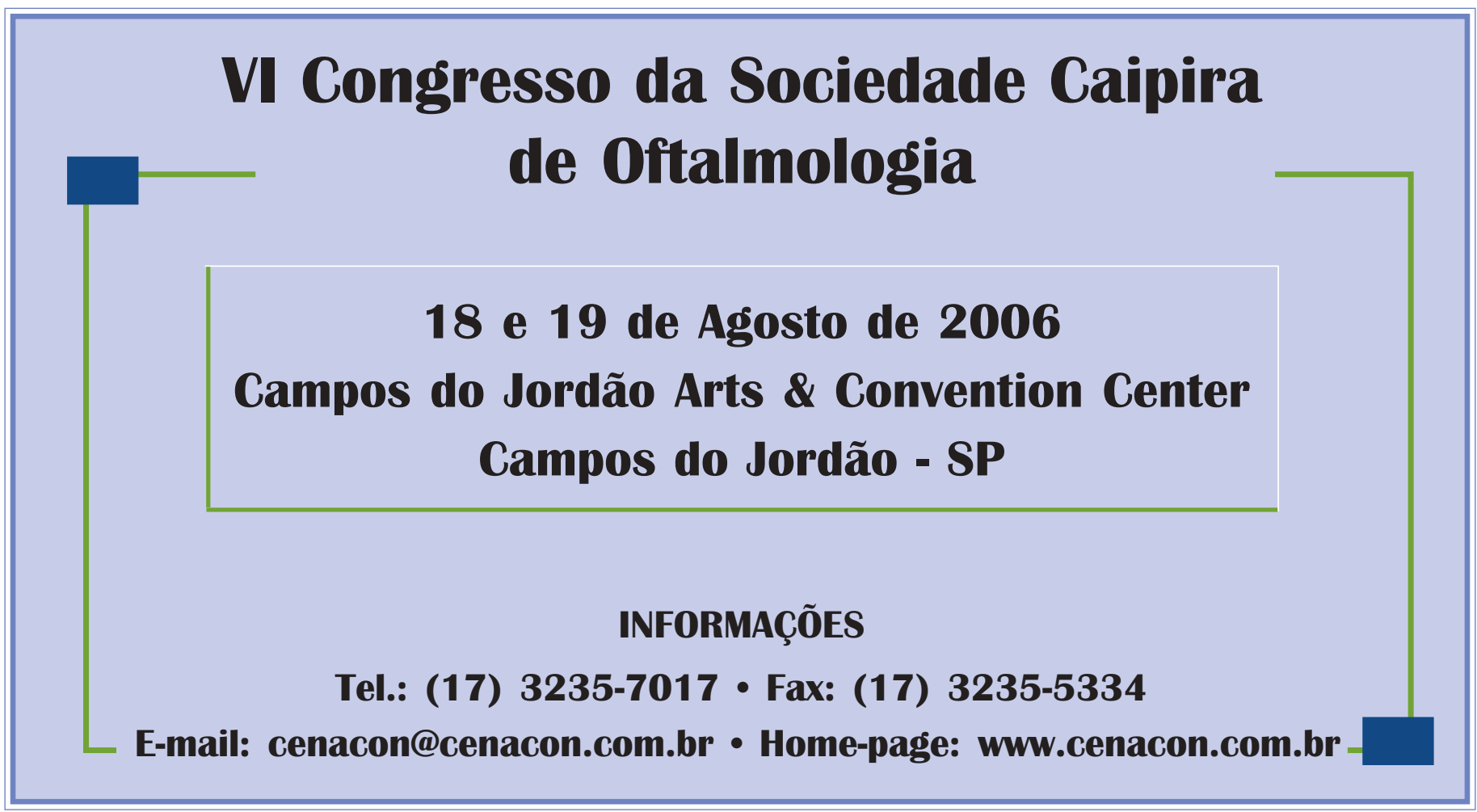

